\title{
Introduction to Future of Urban and Metropolitan Universities
}

\author{
Barbara A. Holland ${ }^{1}$ and Valerie Holton ${ }^{2}$ \\ ${ }^{1}$ Metropolitan Universities Journal Executive Editor Emerita, ${ }^{2}$ Metropolitan Universities Journal Editor \\ Cite as: Holland, B., \& Holton, V. (2019) Introduction to Future of Urban and Metropolitan Universities. Metropolitan \\ Universities, 30(4), 3-8. DOI: 10.18060/23825
}

This is an open access article distributed under the terms of the Creative Commons Attribution License.

Editor: Valerie L. Holton, Ph.D.

On this occasion of the 30th anniversary of the founding of the Coalition of Urban and Metropolitan Universities (CUMU), we have invited past and present executive committee members to share their perspectives on the contemporary prospects, challenges, and opportunities for the members of this thriving organization.

First, you may be interested in a bit of history about the origins of CUMU. In February 1989 a group of campus presidents and representatives of several other higher education organizations met at Wright State University to discuss the proposition that metropolitan located universities were developing distinctive characteristics that reflected their urban locations and relationships. Organized and led by Wright State chancellor Paige Mullhollan, professor Ernest Lynton, and other leaders, the discussion identified the growing concentration of populations and economic activity in America's cities and the new demands and opportunities created by that trend. As cities became the hub of economy and personal opportunity, universities and colleges in cities needed to step up and recognize their roles in contributing to equity, opportunity, and progress. These ideals were formed into a statement called: "Metropolitan Universities: Who Are We?" that highlighted actions and partnerships that we would recognize today as engagement. The story of the development and growth of CUMU is recorded in the 29 years of Metropolitan Universities journal.

Lynton was the founding executive editor of the Metropolitan Universities journal with Karen White as the first managing editor. Volume 1, number 1 launched in spring 1990. The first volume was written by a mix of presidents, provosts, scholars, and a mayor. In his introduction of this defining first issue, Lynton said: 
The theme of this initial issue is identity and culture. We hope that the content will provide a broad-brush overview of the nature and mission of metropolitan universities, a sense of their basic institutional character. In the aggregate, the articles in the issue indicate a number of common attributes shared by all these universities, in spite of their many differences. All are characterized by diversity: diversity of students, diversity of scholarly and professional activity, diversity of constituencies. All accept, albeit to different degrees, the challenge of responsiveness to scholarly and instructional needs of this multiple clientele. All insist on retaining their most basic characteristic: that of being true universities...Metropolitan universities recognize that they must change the way in which this knowledge-centered mission is pursued. The nature, uses, and clientele for knowledge are evolving; the effective interpretation and dissemination of knowledge have become as important as its creation and an ever more diverse clientele needs university-level education. (Lynton, 1990)

By May 1990, a Declaration of Metropolitan Universities was created and signed by the first 46 members of the organization. The declaration described a focus on new approaches to teaching, research, and service that emphasized attention to equity, diversity, relevance, innovation, and accessibility in a context of partnerships with communities, business, culture, and government. The declaration has been updated over the years, but maintains the core focus of equity, access, relevance, and partnerships across member institutions and their cities. The first CUMU conference was in 1993 at University of North Texas.

The second issue of Metropolitan Universities journal in the summer of 1990 focused on "Challenges of Diversity" with provocative articles on the themes of access, retention, campus climate, adult learners, commuter students, and new views of student services and student life in metropolitan campuses, issues that are still important today as each generation of students and the impact of technology requires continuous attention to the ways we support student success. Attention to the student experience and academic success has been a strong theme for CUMU throughout its history, as has the centrality of working partnerships with community leaders and organizations. At the recent 25th conference in October 2019 at Philadelphia, it was exciting to attend many sessions and plenary presentations focused on new strategies for student equity and retention to graduation, and new insights into effective partnerships leading to community, cultural, and economic progress.

An anniversary evokes our need to reflect and also to look at the way forward. Therefore, this issue is similar to the first journal volume in 1990 because we have invited leaders and scholars to reflect on their sense of the state of the metropolitan universities mission and where we are heading going forward. All the past issues of Metropolitan Universities journal are available 
online, so you may wish to read those early two issues to appreciate our origins as an association that continues to seek to contribute to greater equity and success for our students, our institutions, and our communities.

The contributions in this issue, written by institutional leaders, offer very bold ideas. Higher education is changing rapidly and unevenly across America. Some institutions, represented here, are thinking and acting in bold ways to recapture public support, improve student progress, and re-invent the ways we fund our institutions and the ways we do research and teaching, among other large changes. The large-scale change higher education is experiencing now is not easy and often painful, especially when change leads to closures. However, the papers in this issue and other news gives me a sense of optimism. Higher education is entering an era of big changes. The world's population and enterprises are concentrated in cities. The experience of change across CUMU institutions will be of great value to others seeking to find the way forward to serve educational needs and a capacity for future discoveries and innovations.

\section{In This Issue}

In the first article in this volume, Robert Caret, chancellor of the University System of Maryland, describes what he learned in his early career as an administrative leader at urban institutions such as San Jose State University, Towson University and others, which he calls primary access institutions. Caret sees these access-oriented institutions as successful in expanding access to full participation in society, leading to contributions to the local work force, culture, and social change. Today, as a leader of a large, multi-campus system, Caret builds on these values of access institutions to remind us that education is not just to create opportunity for the individual's personal success, but also to inspire the educated individual to recognize their social and public responsibilities. Caret says: “...we have an obligation to make sure our society is provided with the graduates it needs, graduates that have the education, the cultural and intellectual underpinnings, and the perspectives necessary to enable them to take their place as enlightened and progressive members and leaders of a democratic society." Caret describes a straight-forward approach to encouraging students to develop the skills of an engaged citizen that appreciates and participates in democracy. Through his experiences, Caret observes the need to move from campus approaches to engagement that involve only some students, to an approach that integrates civic education, civic engagement, and civic responsibility into curriculum and institutional culture. He offers a thoughtful and practical description of the importance of attention to the development of each of these three attributes, which require different approaches. Caret also shares examples of how the institution can demonstrate its own focus on civic responsibility by increasing student voice on campus, engaging faculty, staff, and students in improving local schools, and collaborating with other universities nearby. 
Buffalo State College provides an exciting and inspiring story of a city that is emerging into a new era of opportunity and success through partnerships between the college and many other entities to welcome new groups moving into the city and facilitate their well-being and success. President Katherine S. Conway-Turner describes how the city, the college, schools, foundations, the government, and non-profits work together to help new arrivals with ways to learn about their new home and provide necessary services to help them settle in and become productive members of a city that is growing again after the loss of manufacturing. The depth of partnerships and the creative approaches to supporting language training, student graduation rates, transitioning from school to college, small business development, and more, is impressive. President Conway-Turner says: "Our campus today has a layered approach to addressing the concerns of many of the newest members of our community. We extend our campus to support children, adults, and all family members who come to western New York looking for a better place to live, grow, and, hopefully, thrive."

President Devorah Lieberman of the University of La Verne and Shannon Capaldi, director of the president's office, write about the growing image problem related to going away for college. High costs of going away to college is leading to a growing image that a degree isn't worth it. The authors note that stayers who are encouraged throughout their schooling to attend a local college can both improve the economic and social strength of their community and also feel proud of their education. They contrast brain drain which can lead students away, never to return home, with Brain Remain that can enrich both the student and the region. As discussed by the authors, "students choosing to stay close to home for college would lead to feeling that, while they had choices to study close to home or at a distance, they made the choice related to pride in their community. Communities and K-12 educators should be cultivating the talent and intellect of all their students and rely on the students' emotional attachment and financial investment to stay close to home, ergo Brain Remain." The authors offer suggestions and literature relevant to the strategies for encouraging students to consider remain, which may reduce skepticism about degree values.

Richard Guarasci, president emeritus at Wagner College, describes the dangers of the current economic model that higher education is following today and offers an alternative vision for higher education organization that is based in large part on the creation of greater value to the public and the students. Guarasci says: "The alternative to the pure market model is the engagement model. This approach values collaboration, integration, and partnerships over competition and revenue maximization. The engagement approach will require a major shift within the culture of higher education leadership and its success will demand courage by trustees, regents, and alumni. Additionally, it will need faculty members and administrators to be their best creative selves." He proposes partnerships across universities and colleges and other business, industries, and organizations for every aspect of operations, and to intentionally develop a teaching/research agenda that aligns with regional assets, challenges, and 
opportunities, among other ideas. Given the examples of some universities already seeking networks of partnerships to increase impact on community progress, his model has real potential going forward.

The team of Guenther, Swanstrom, and George at the University of Missouri-St. Louis (UMSL) report on their Anchor Institution initiatives in the two-mile square area around the campus. Post-industrial cities like St. Louis are now experiencing increasing poverty, hunger, homelessness, loss of businesses, and other inequities of opportunity in the suburbs. St. Louis is distinctive in that it has the most fragmented suburbs in the nation with 88 municipalities overall, and 30 of those municipalities are in the UMSL region. As discussed by the authors, "one of the findings from the data was how deeply UMSL was involved in the anchor footprint. UMSL has 370 full-time, part-time, and student employees and over 4,000 alumni who live within the twomile radius. The university has deep connections with the people in this community beyond its physical placement, professional connections, and public land grant mission. The data collection made it clear that our well-being was closely connected to the fate of these communities." The case study presented by UMSL provides useful insights into the difficulty of organizing collective actions across many small entities that don't have much bandwidth. The authors provide tools and tips that have led to notable progress.

Wim Wiewel, president of Lewis and Clark College, and professor Jerusha Detweiler-Bedell offer insights into the views of engagement in a private liberal arts college environment. As discussed by the authors, "liberal arts colleges are now being challenged to demonstrate their relevance and value. Their future is, in part, predicated on their success in building stronger, more strategic, and mutually beneficial relationships beyond their campus, specifically by collaborating with and adding value to the cities and metropolitan areas in which they are located." Over the last decade the college has been increasing the integration of engagement with public issues in the curriculum using a variety of methods including integrated internships, exploring historic places, studying public policies, and proposing innovations. At this college learning is a shared endeavor; college students are learning and discovering through interactions with people in the community so that all are ultimately benefiting from the partnership.

William J. Fritz and Ken Iwama share amazing story of the College of Staten Island's Legacy Trilogy initiative. Their article opens with a compelling statement: "The degree to which urban and metropolitan colleges and universities can have a positive impact on their respective is heavily influenced by the nature and extent of their connectedness to, and alignment with, civic need." In 2012, leadership of the college began to engage in public discussions and recognition of the Legacy of Institution, the Legacy of Place, and the Legacy of Mission in ways that acknowledged the historical and problematic past of the institution and opening a new way to embrace its modern mission as Staten Island's anchor institution serving a highly diverse population. Their article describes a three-year process to acknowledge the past narrative, which 
has led to new changes that are based in engagement with current community needs and interests.

In 2015 Marquette University realized it needed to take a much more focused approach to community engagement around their campus and the wider urban region. President Lovell and his colleagues provide a clear and logical story of the internal and external processes that have, over five years, created a more focused agenda of engagement and the necessary partnerships and infrastructure to implement, guide, and assess the work. This article offers an excellent guide on how to work across sectors to create more equitable external partnerships and more inclusive community engagement. An initial focus on a partnership center near campus led to the recognition of the need for more internal coordination and leadership of engagement, and better ways for community to connect to the university. As engagement became more intentional, working groups were formed to promote best practices in engagement, leading to discussions about the recognition of faculty using engagement methods in teaching and research. Recently a new task force has been created to consider ways to coordinate efforts across higher ed and corporate entities to encourage collaboration and reduce overlap. The Marquette story is impressive in its innovative approaches to building internal and external connections to support effective engagement.

In sum, this issue of Metropolitan Universities journal reveals that though people often joke that higher education institutions don't change, these articles tell us otherwise. Change is everywhere in higher education. When CUMU founders met at Wright State in 1989, there were mostly two generations of faculty across most universities, today there are at least four generations with Gen $\mathrm{Z}$ on the horizon as the fifth. Change and adaptation is an essential institutional skill. Students, the community, business and government leaders, alumni, and our faculty and staff are thinking about and enacting changes in education every day, be it a simple fix or a giant leap into a largescale change initiative. The Coalition of Urban and Metropolitan Universities distinguishes itself in several ways; it is collaborative and members support each other and share ideas about challenges and opportunities. This issue specifically aims to foreshadow the way forward for higher education in an increasingly urbanized world. The nature of this topic has called authors to look at the past as a way of understanding what's ahead. We thank the authors for their thoughtful and candid contributions. 